\title{
Infantile respiratory syncytial virus and human rhinovirus infections: respective role in inception and persistence of wheezing
}

\author{
Giovanni A. Rossi ${ }^{1}$ and Andrew A. Colin ${ }^{2}$ \\ Affiliations: \\ ${ }^{1}$ Pulmonary and Allergy Disease Paediatric Unit, Istituto Giannina Gaslini, Genoa, Italy. \\ ${ }^{2}$ Division of Pediatric Pulmonology, Miller School of Medicine, University of Miami, Miami, FL, USA.
}

\section{Correspondence:}

Giovanni A. Rossi, Pulmonary and Allergy Disease Paediatric Unit, Istituto G. Gaslini, Via G. Gaslini 3-5, 16147 Genoa, Italy.

E-mail: giovannirossidospedale-gaslini.ge.it

ABSTRACT There is evidence that respiratory viruses play a key role in the development and exacerbation of obstructive respiratory diseases in children. This review attempts to juxtapose the separate profiles and prototypes of pathogenenetic mechanisms represented by the two most common amongst such viruses: respiratory syncytial virus (RSV) and human rhinovirus (HRV).

RSV represents the most common agent of severe airway disease in infants and young children, and is predominant in winter months. Large epidemiological studies have revealed an unequivocal relationship between RSV infection and subsequent wheezing into childhood, thought to be related to long-term changes in neuroimmune control of the airways rather than allergic sensitisation.

HRV is a highly diverse group of viruses that affect subjects of all ages, is ubiquitous and occurs yearround. In contrast to RSV, infections with HRV cause minimal cytotoxicity but induce a rapid production of cytokines and chemokines with amplification of the inflammatory response. The susceptibility to HRVinduced bronchiolitis and subsequent wheezing appears to be linked to individual predisposition since it is often associated with a family or personal history of asthma/atopy.

Thus, RSV probably serves as an "inducer" rather than a "trigger". Conversely, HRVs seem to serve as a "trigger" rather than an "inducer" in predisposed individuals.

@ERSpublications

Comprehensive overview of the different roles of RSV and HRV in the pathogenesis of recurrent wheezing in childhood http://ow.ly/CmRML 


\section{Introduction}

Although there is evidence that asthma can develop at any age and that its phenotypic expression can vary in different life stages, in most individuals the disease has its origin in early life [1]. Current studies suggest that both genetic characteristics and epigenetic mechanisms may underlie the complex associations between exposure to environmental factors in early childhood and wheezing and asthma in later life $[2,3]$. There is little doubt that respiratory viral infections constitute major environmental risk factors for the development of obstructive respiratory disease in children [2-5], disorders that are characterised by a sequence of injury, inflammation and, ultimately, airway obstruction $[6,7]$. The most common viruses identified during early-life wheezing illnesses are respiratory syncytial virus (RSV) and human rhinovirus (HRV) [8]. RSV is the aetiological agent involved in the majority of lower respiratory tract infections (LRTIs) in the first months of life. Multiple epidemiological studies have clearly demonstrated that history of severe RSV bronchiolitis is frequently associated with subsequent persistent wheezing, childhood asthma or both [9-13]. While murine models of RSV revealed pathogenetic mechanisms related to upregulation of neuroimmune mediating genes [14], the pathogenesis of recurrent wheeze after RSV bronchiolitis is still poorly understood, it also remains unclear what factors govern the selection of some individuals and not others to develop obstructive respiratory symptoms in later childhood [15-17]. If RSV is the most frequent cause of LRTIs in young infants, HRVs are the most commonly identified virus involved in wheezing exacerbations in older infants, preschool-aged and school-aged children and adolescents [17-22]. HRV seems to be less harmful to bronchial structures compared to RSV, yet it appears to provoke a sustained airway inflammatory response and induce respiratory symptoms, predominantly in predisposed individuals [17-23]. Of note is that HRV more than RSV infections in the first years of life constitute a significant risk factor for the presence of asthma, at least in "high-risk" children populations [22]. An important step to understand the pathogenesis of recurrent wheezing episodes and asthma in childhood is, therefore, to appreciate the different roles played by RSV and HRV in the inception and exacerbations of these disorders.

\section{RSV and respiratory infections}

RSV is a single-stranded RNA virus of the Paramyxoviridae family whose genome includes 10 genes, encoding seven structural and four non-structural proteins [3]. Two viral glycoproteins, designated G (large glycoprotein) and F (fusion glycoprotein), are involved in virus-host cell attachment and cell fusion. Annexin II has been identified as a potential RSV receptor on airway epithelial cells, while L-selectin/ CD62L and CX3CR1 appear to be the potential receptors for G-protein on leukocytes and immune-effector cells [23]. Nowadays, RSV diagnosis largely relies on nucleic acid/PCR-based tests. Strictly speaking, the high sensitivity of these tests may complicate clinical interpretation, as the presence of small amounts of viral targets may not necessarily prove their pathogenetic role. However, prospective case-control studies in asymptomatic and symptomatic young children have shown that a positive RSV test result is almost always of clinical relevance, independent of viral quantity [24, 25].

RSV epidemics are seasonal, with peak infection occurring during late autumn/winter to early spring in the northern hemisphere [8,23-28]. RSV is ubiquitous and nearly all children are infected by 2 years of age or following two RSV seasons, and LRTIs due to RSV are a leading cause of hospitalisation during the first year of life [7, 22-24]. However, only a subset of the infected children develops severe disease [8, 23-27]. In addition to the variability in severity among different RSV seasons, a number of host-related characteristics may increase the risk of hospital admission rates for RSV-induced LRTI in young children [8, 23-28]. These include prematurity, low birth weight, male sex, day care attendance, the number of siblings living permanently in the child's household and tobacco exposure $[29,30]$. One constant characteristic is that infants hospitalised with RSV-induced LRTI tend to be younger than those hospitalised with other respiratory viruses; infection rates for RSV peak in infants aged $\leqslant 3$ months $[29,30]$. The severity of RSV-induced LRTIs during the first few months of life (especially in premature infants) may be explained by the incomplete development of the respiratory system, the small airway diameters and also the immature immune system. Studies on the immune response in primary RSV infection have demonstrated that infants aged $<9$ months produce fewer antibodies (IgM, IgG, IgA and secretory IgA) to both glycoprotein $\mathrm{F}$ and glycoprotein $\mathrm{G}$, when compared to older infants and young children [31]. In infants, the defective production of antibodies leads to a type III immune complex reaction between maternally transmitted IgG and RSV antigen with recruitment and activation of inflammatory cells that damage the airway structures [32]. It has been shown that the presence of maternally derived IgG, which contains abundant activity against glycoprotein F, may suppress the development of anti-F IgA during primary RSV infection [33]. Because of their ability to block viral spreading, IgA and secretory IgA antibodies play an important role in the mucosal defence against respiratory viruses.

The lack of protective antibodies at the site of infection in young infants with bronchiolitis favours viral replication, leading to high RSV viral load, a factor that has been shown to correlate positively with the clinical severity of the disease and the length of hospital stay [34]. Viral replication directly increases the 
number of infected cells and, therefore, the extension of the damage to the airway. These observations may, at least partially, explain not only the severity of primary RSV infection but also the longer convalescence period reported in young infants.

\section{RSV infection and host immune response}

RSV takes a uniquely pernicious position among all respiratory viruses causing respiratory tract infections in young infants due to its cytopathic activity. However, besides the direct cytopathic effect of the virus, the local host inflammatory response plays a fundamental role in the development of the signs and symptoms that characterise the disease. This combined effect of the virus and the inflammatory response to it leads to epithelial damage, sloughing off of epithelium, mucus production and ultimately airway obstruction [35]. In both humans and experimental animals, RSV replication is followed by necrosis of the bronchiolar epithelium with subsequent submucosal oedema, recruitment of polymorphonuclear leukocytes, lymphocytic peribronchiolar infiltration and bronchoconstriction. Mucus secretion increases in both quantity and viscosity and, when mixed with cellular debris and fibrin, severe obstruction of the airway lumen occurs. Airway epithelial cells appear to be highly permissive to RSV, as demonstrated by the high viral replication and the cell cytotoxicity observed after experimental exposure of human bronchial epithelial cells (BECs) to the virus [36]. In air-liquid interface cultures, generated from nasal and bronchial brushes from healthy preschool children, RSV infection appeared to be localised to apical ciliated epithelial cells, with no detectable infection of goblet cells [37]. RSV-induced apoptosis was associated with epithelial cell sloughing and occasional syncytium formation, which were more noticeable in bronchial than nasal epithelial cell cultures [37]. The cytopathic effect inherent to RSV is permitted and amplified by the presence of a potent but defective host immune response [38]. In human infections, viral RNA, arising during viral replication, is first recognised by airway epithelial cells through pattern recognition receptors that include Toll-like receptors (TLRs) and retinoic acid-inducible gene-I-like receptor family members (fig. 1a) [39]. This viral antigen recognition leads to nuclear factor $-\kappa B$ activation with production of interferon (IFN)- $\beta$, a type-I IFN, which in turn and via an autocrine mechanism enhances its own synthesis and initiates the production of IFN- $\alpha$, CXCL 8 and type-III IFN (IFN- $\lambda$ ) by airway epithelial cells and innate immune cells $[37,39]$. These cytokines have the ability to recruit and activate polymorphonuclear leukocytes and natural killer cells and, importantly, also trigger programmed death of infected airway epithelial cells as a mechanism of limiting viral replication and spread to neighbouring cells [39]. Airway dendritic cells carry viral antigens to local lymph nodes and present them to CD4 ${ }^{+} \mathrm{T}$-cells that activate $\mathrm{B}$-lymphocytes and $\mathrm{CD} 8^{+} \mathrm{T}$-cells. These cells migrate back to the infected airways where they recruit additional inflammatory cells (fig. 1b). Unfortunately, both RSV nucleoproteins and RSV G-protein can antagonise the immune response to infection (fig. 2) [37, 40, 41]. In immortalised cell lines, RSV efficiently suppresses the production of type I IFN using its two unique nonstructural proteins, NS1 and NS2 [40]. These are targeting by at least three key signalling molecules of the cellular type-I IFN induction and response pathways, namely: 1) tumour necrosis factor (TNF) receptor-associated factor-3, a strategic integrator of multiple IFN-inducing signals; 2) inhibitor- $\kappa \mathrm{B}$ kinase $\varepsilon$, a key protein kinase that specifically phosphorylates and activates IFN regulatory factor-3; and 3) STAT2, the essential transcription factor for IFN-inducible antiviral genes [42]. In addition to NS1 and NS2, the G-protein itself seems to play a major role in immune evasion of RSV. This protein is highly glycosylated, which may impede immune recognition, and its high variability allows easy escape from neutralising antibodies [43]. Furthermore, during viral replication, a soluble form of G-protein (sG-protein) is released and binds RSV-specific antibodies, thus, reducing the concentrations available for RSV neutralisation [44]. Finally, the sG-protein functions may act as a TLR antagonist, downregulating TLR2-, TLR4- and TLR9-mediated inflammatory responses [41]. A defective production of type-II IFN, i.e. IFN- $\gamma$, a cytokine critical for the immune response against viral infections, has been described in infants with RSV bronchiolitis [45]. The reduced IFN- $\gamma$-dependent viral clearance may be related to reduced T-helper (Th) 1 function, based on the observation that acute RSV bronchiolitis elicits an imbalance in Th1/Th2 cytokines present in airways secretions and produced by peripheral blood mononuclear cells (PBMCs), including a shift toward a Th2-type response [45]. Such preferential promotion of Th2-like responses in the airways with local production of interleukin (IL)-4, IL-5 and macrophage inflammatory protein-1 $\beta$, and infiltration and activation of eosinophils, has been reported when RSV infection occurs during early infancy [46]. This decrease in IFN- $\gamma$ production by PBMCs in infants with RSV bronchiolitis contributes to the severity of the disease since it is associated with a depressed lymphoproliferative response [47].

Interestingly, studies have shown that patients with asthma and atopic disease have a deficient IFN- $\gamma$ response, with significantly lower levels reported as early as birth [48], and that lower cytokine responses, including IFN- $\gamma$, to RSV by cord blood mononuclear cells have been seen in children with a parental history of allergy or asthma [49]. Furthermore an inverse relationship between cord blood IFN- $\gamma$ responses 


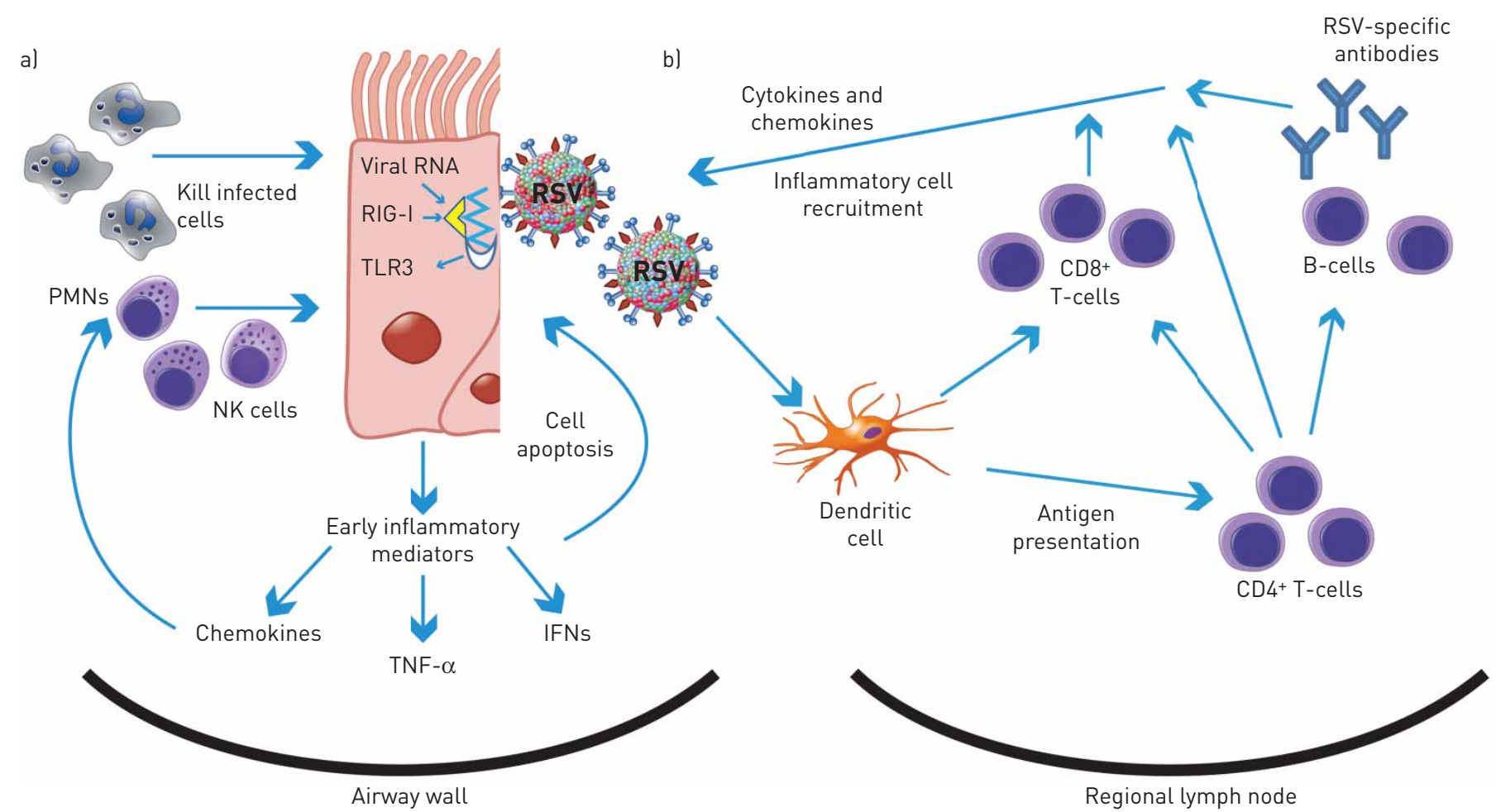

FIGURE 1 Respiratory syncytial virus (RSV) infection and the host. The innate and adaptive immune response to RSV. a) Viral RNA, arising during viral replication, is recognised through Toll-like receptor (TLR)-3 and retinoic acid-inducible gene (RIG)-I-like receptors. Cellular infection triggers the release of early inflammatory mediators (e.g. interferons (IFNs) and tumour necrosis factor (TNF)- $\alpha$ ) and chemokines (e.g. CXCL8 and CXCL11). Type I IFNs upregulate pro-apoptotic factors in the epithelial cells, while TNF- $\alpha$ and chemokines recruit natural killer (NK) cells and polymorphonuclear leukocytes (PMNs) that have the ability to kill the infected cells, thus limiting viral replication and spread to neighbouring cells in the first days of infection. b) RSV can also infect dendritic cells that carry viral antigens to regional lymph nodes. Presentation of viral antigens to CD4 ${ }^{+}$T-lymphocytes occurs and primed T-cells activate B-lymphocytes and $\mathrm{CD}^{+} \mathrm{T}$-cells. They all migrate back to the infected epithelium with further release of mediators and recruitment of additional inflammatory cells, including PMNs and mononuclear cells. Data from [39].

and the frequency of symptomatic RSV-induced respiratory tract infections has been demonstrated in infants within the first year of life [50].

Infection of airway epithelial cells by RSV initiates an inflammatory response through the release of pro-inflammatory mediators, such as TNF- $\alpha$, eotaxin, interleukins such as IL-1 $\alpha$, IL-1 $\beta$, IL-6 and IL-8, and chemokines, such as CCL5, CXCL10, CXCL11 and TRAIL (TNF-related apoptosis-inducing ligand), which in concert contribute to activation of leukocytes at the site of the infection and may amplify the injury to airway structures $[37,38,51]$. In parallel, however, counter-regulatory cytokines, such as IL-4 and IL-13, are also produced during RSV infection [52]. In response to IL-4 and IL-13, monocytes differentiate into "alternatively activated macrophages" that display anti-inflammatory activities and, in mouse models of RSV-induced infection, contribute to resolution of lung disease [53]. Other cytokines with potential "anti-inflammatory" activity, such as IL-6 and IL-10, were detected in clinical studies from nasopharyngeal secretions of infants with RSV-induced LRTIs [54-56]. Therefore, viral antigen recognition induces a vigorous production of a variety of mediators that activate the innate and adaptive immune responses to limit viral replication. This disproportionate release of pro-inflammatory mediators induces a massive infiltration of monocytes and polymorphonuclear cells that, in addition to amplifying the cytopathic effect of the virus, may misdirect the immune response. Viral clearance is rendered less effective by unfavourable induction of a Th1-type response, described in young infants with RSV bronchiolitis, and together with the ability of RSV constituents to antagonise the host immune system they enhance disease severity. Thus, in addition to co-opting host genes for replication to achieve an optimal balance between viral and cellular gene expression, the virus is able to protect the infected epithelial cells from the host inflammatory-immune reaction to gain replication advantages.

\section{Role of RSV in wheezing/asthma inception}

The connection between RSV infection and the development of recurrent wheeze and asthma has long been debated. There is clear evidence that an increased risk of wheezing is present in children who have 


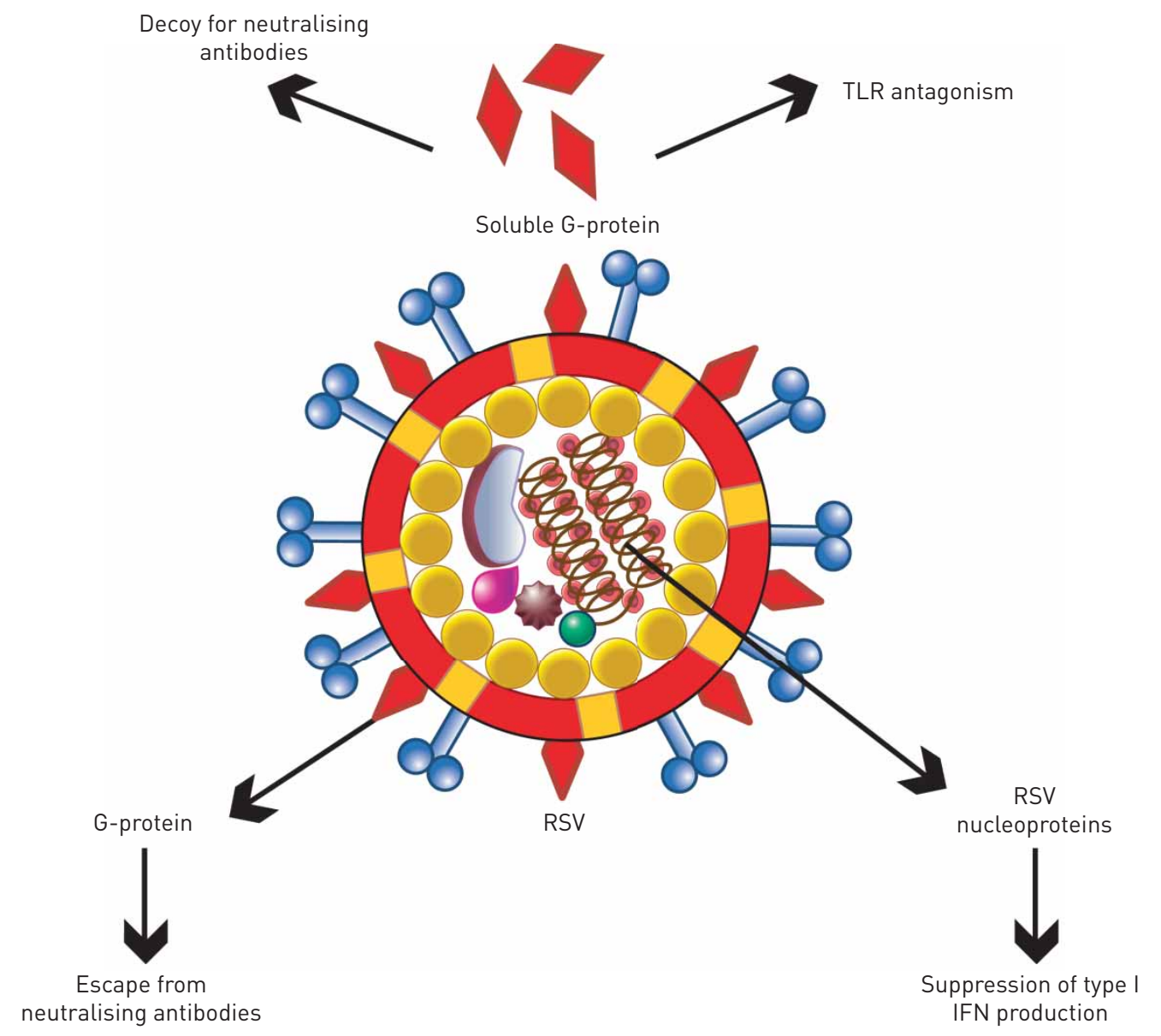

FIGURE 2 Respiratory syncytial virus (RSV) proteins antagonise the host immune response. The high glycosylation and structural variability of surface G-protein may impede immune recognition and favour an easy escape from neutralising antibodies. The soluble form of the G-protein, released during viral replication, binds RSV-specific antibodies diminishing the concentrations available for RSV neutralisation. The soluble form of the G-proteins can also inhibit the Toll-like receptor (TLR)-mediated type-I interferon (IFN) induction, amplifying the suppressive effect of RSV nucleoproteins, NS1 and NS2, on IFN production.

had a severe RSV infection in early life $[9,15,57]$, but the question remains as to whether RSV is a veritable risk factor or rather a marker of predisposition to recurrent wheeze and asthma in susceptible individuals. During the past 10 years, genetic studies have demonstrated the existence of various susceptibility genes, possibly associated with the development of severe bronchiolitis, and several hundred single nucleotide polymorphisms (SNPs) were studied [58]. Specific genes associated with the risk of severe bronchiolitis can be divided into the following four categories: 1) airway mucosal responses; 2) innate immune responses; 3) adaptive immune responses; and 4) allergic responses. A major concern of the SNP studies related to bronchiolitis is that most genetic associations have not been confirmed to date. In contrast, two prospective epidemiological studies have supported the hypothesis that RSV-induced LRTI is a real independent risk factor for recurrent wheeze and asthma. In a prospective study on children enrolled in a large longitudinal study in Tucson (AZ, USA), STEIN et al. [9] showed that, compared to children who did not have a LRTI, those who had a RSV-induced LRTI in the first years of life were 4.3 and 2.4 times more likely to have frequent wheeze by the age of 6 and 11 years, respectively. Then, the risk progressively decreased, until it became insignificant by 13 years of age. There was no link between RSV-induced LRTI and development of allergic sensitisation [9]. At 11 years of age the children who had had RSV-induced LRTI in the first years of life also had significantly more bronchial obstruction (decreased forced expiratory volume in $1 \mathrm{~s}$ ) compared to the control group [9]. The difference, however, was not significant after inhalation of albuterol, suggesting a reversible airflow limitation, i.e. functional rather than structural dysfunction of the respiratory system. In a prospective, carefully controlled study in Borås, Sweden, Sigurs et al. [16] found a 30\% cumulative incidence of asthma among 7-year-old children who had been hospitalised in infancy with severe RSV bronchiolitis, compared to 3\% in a well-selected control group. In addition, $23 \%$ of physician-diagnosed asthma was found in post-RSV children compared 
to $2 \%$ of controls. In a subsequent report of the same population, by 18 years of age the RSV group still had an increased prevalence of recurrent wheeze/asthma compared to controls (39\% versus 9\%), as well as clinical signs of allergy ( $43 \%$ versus $17 \%$ ) and sensitisation to perennial allergens (41\% versus $14 \%$ ), suggesting a link between RSV infection and the development of atopy [57]. Of note is the observation that in the latter study [57] the rate of sensitisation to perennial allergens in the control population (14\%) was lower than that reported by other studies in Sweden (20-30\%) [59]. Discrepancies between the Tucson and the Borås studies may be related to the differing severity of the original infections or to differences in environmental factors and/or the genetic background of the children studied. However, taken together, the two studies suggest a 30-40\% likelihood of recurrent asthma-like episodes after early-life RSV-induced LRTI. This suggestion is supported by a recent prospective, multicentre trial performed in Europe, USA and Canada, concluding that the relative risk of recurrent wheezing during preschool years may be significantly decreased by RSV prophylaxis with palivizumab [60]. The decrease was observed in non-atopic children but not in children with an atopic background, suggesting that RSV may play a significant causative role in the pathogenesis of recurrent wheeze only in the absence of genetic predisposition to atopy [60]. A substantial pathogenetic role of RSV in inducing recurrent wheezing is similarly shown by the recent observation on the efficacy of palivizumab in reducing wheezing days in healthy, late preterm infants [22].

\section{Neurogenic inflammation in RSV infection}

Experiments performed on animal models have shown that early-life RSV infection induces an abnormal neural control resulting in airway hyperreactivity [61]. RSV-induced neurogenic inflammation appears to potentiate the cholinergic and excitatory noncholinergic, nonadrenergic neural pathways that favour bronchoconstriction and mucus production and increase vascular permeability. In young rats, stimulation of sensory nerves in the respiratory tract during RSV infection induces an exaggerated neurogenic activation mediated by selective upregulation of the high-affinity substance $P$ receptor, termed neurokinin 1 receptor (NK1) [62]. Substance $\mathrm{P}$ is a neuropeptide that functions as a neurotransmitter and a neuromodulator, and in addition to its role in pain perception, is involved in neurogenic inflammation [61]. In the same experimental model in the airways of young rats, a large increase in the expression of nerve growth factor (NGF) and its high-affinity tropomyosin-related kinase A receptor has been demonstrated [62]. NGF has been long identified as a key regulatory element of neuronal development and responsiveness; however, it also modulates immune responses by controlling expression of genes that encode the precursors of substance $\mathrm{P}$ and other peptide neurotransmitters in sensory neurons [63]. Specifically, NGF has been associated with allergic inflammation and airway hyperresponsiveness in animal models, as well as in humans [64]. Neurotrophic factors (such as NGF) and their receptors are synthesised not only by nerve-associated cells and neurons, but also by several non-neuronal cell types involved in RSV infection, including epithelial cells, monocytes and macrophage, mast cells, and T- and B-lymphocytes [65-67]. Thus, RSV induces a three-pronged abnormal neural control that includes: 1) NGF overproduction; 2) NK1 receptor overexpression and activation; and 3) upregulation of the release of substance $\mathrm{P}$. These changes drive short- and long-term modifications in the distribution and reactivity of sensory and motor nerves in the respiratory tract, and are deemed to play a significant role in the pathogenesis of nonspecific airway hyperreactivity, the sequel of RSV infection [61, 62, 65]. An added pathogenetic role of the overexpression of NGF and its high affinity tropomyosin-related kinase A receptor is that they confer protection against virus-induced apoptosis, inhibiting programmed cell death in the infected bronchial epithelium and favouring RSV viral replication through infection of neighbouring cells [65]. The hypothesis that neurogenic inflammation may be involved in the pathogenesis of the human infection is supported by the observation that neurotrophic factors and receptors may be overexpressed in the airways of mechanically ventilated infants with RSV-induced LRTI [14].

\section{HRV and respiratory infections}

HRVs belong to the genus Enterovirus of the Picornaviridae family. They are small, nonenveloped viruses with a single-stranded, positive-sense RNA genome [68]. Infectious virions consist of an icosahedral protein shell (capsid) that surrounds and protects the genome (a single, positive-stranded RNA molecule of 7400 nucleotides). To date, there are more than 150 recognised serotypes of HRV that differ according to their surface proteins and the receptor they bind to at the surface of epithelial cells in the respiratory tract [68]. Strains that bind to intercellular adhesion molecule (ICAM)-1 belong to the so-called "major group HRVs", while the "minor group HRVs", including 10 strains, bind to the low-density lipoprotein receptor [69]. According to their sequence structures, HRVs are further classified into three main phylogenetic species: HRV-A, HRV-B and HRV-C $[66,70]$. One striking characteristics of HRVs is the ability to replicate rapidly and demonstrate high mutation rates, resulting in distinct genetic diversity [71]. Since most HRVs replicate best at $33-35^{\circ} \mathrm{C}$, it was long thought that infections were limited to the upper airways where the temperature of the mucosal surface is relatively low. However, the presence of HRVs in 
the lower airways in most volunteers, following experimental infection of the upper airway [72], and the detection of the virus in bronchial biopsies from infants during naturally occurring infections proves that HRV also frequently infects the lower airways [73]. People of all ages may be affected by the infection with an incidence that is inversely proportional to age: by 2 years of age $91 \%$ of children have antibodies against HRVs [74-77]. In contrast to RSV, infections with HRVs have been shown to occur throughout the year with a large number of distinct strains circulating each year [75-78]. In the northern hemisphere, HRVs appear to be the most frequently isolated microorganism in summer, a time of year when rates of respiratory illness are generally lower [78]. Higher incidence for HRV infection has been described from September to November and from April to May, but in some years (and in some geographical areas) spring was reported to be the more important time for HRV transmission [78]. Several reports suggest that there is a seasonal variability in severity with peaks during cold seasons, probably related to the seasonal distribution of specific strains [75-79]. LeE et al. [79] showed that HRVs in infants were more likely to cause moderate to severe illness in the winter months compared with summer, with a peak seasonal prevalence in spring and autumn. In that study, HRV-A and HRV-C were more likely to cause moderate to severe illness compared with HRV-B. Because of the difficulties of viral culture, the limited availability of antigen detection tests and the insensitivity of serology, HRV diagnosis relies almost entirely on nucleic acid/PCR-based tests [80]. However, the high sensitivity of PCR is also a limitation in HRV infection, as the presence of virus nucleic acid in respiratory secretions of a patient with respiratory symptoms does not prove that the virus is the cause of the symptoms. Indeed, HRVs are detected not only in children and adults with serious LRTI [21, 81, 82], but are also frequently found in asymptomatic children and adults [83, 84]. As an example, using PCR LEE et al. [79] found HRV alone or with other respiratory virus in the nasal lavages of $58.3 \%, 66.4 \%$ and $41.5 \%$ of infants with moderate to severe illnesses, mild illness and no symptoms, respectively.

\section{HRV infection and host immune response}

The airway epithelial cell is the primary site of HRV infection and replication. In contrast to observations for the majority of respiratory viruses, including influenza, parainfluenza, adenovirus and RSV, HRVs have been shown to induce minimal, if any, cytotoxicity [85-87]. In vitro, the different rhinovirus serotypes seem to differ in their cytotoxic capacity, but in most cases cytotoxicity appears to be cell density dependent, i.e. only observed in sparsely seeded cultures exposed to the virus, conditions that are not mimicked in the in vivo situation [88]. Rather than cytotoxic effects, experimental or naturally occurring exposure of airway epithelial cells to HRV normally induces a virus-specific cytopathic effect, which is associated with an inflammatory reaction [89]. In experimentally induced infections of normal adult volunteers, HRVs trigger nasal vasodilation and increased vascular permeability, leading to obstruction and rhinorrhoea, but no histopathological changes were observed in nasal biopsy specimens [90]. Exposure of airway epithelial cells to HRV leads to the release of pro-inflammatory products that help initiate antiviral responses by enhancing leukocyte recruitment and activation. In experiments performed on cell culture it has been shown that interaction of purified HRV with the epithelial ICAM-1 receptor induces rapid production of cytokines, chemokines and growth factors. This also occurs when the virus has been rendered replication deficient; indicating that generation of these mediators is triggered directly by viral binding [91]. Although HRV binding to ICAM-1 induces production of pro-inflammatory products, an even stronger activation of the infected epithelium seems to depend on the ability of the virus to replicate and involves the recognition of double-stranded (ds)RNA, generated during the HRV replication cycle (fig. 3) $[75,92,93]$. The subsequent release of cytokines and chemokines results in an amplification of the inflammatory response to infection, presenting with symptomatic colds and asthma exacerbations [82, 94]. Increased levels of granulocyte-macrophage colony-stimulating factor (GM-CSF), RANTES (regulated on activation, normal T-cells expressed and secreted), IL-6 and IL-8 have been reported following HRV infection, and IL-6 and IL-8 concentrations in nasal secretions have been shown to have a direct correlation with symptom severity in experimental HRV colds [75, 82, 89, 92, 94]. The observation that experimentally induced infections in humans may provoke clinical symptoms in the absence of histopathological changes [90] further supports the pathogenetic role of the inflammatory response of the host [76]. Indeed, cytokines, chemokines and growth factors, such as IL-1 $\alpha$, IL-1 $\beta$, monocyte chemoattractant protein-1, IL-16, IL-11 and GM-CSF, secreted by airway epithelial cells after exposure to $\mathrm{HRV}$, can also modulate the survival, proliferation or activation of various populations of inflammatory and effector cells [92]. Other growth factors can contribute to airway remodelling by stimulating angiogenesis or regulating fibroblast proliferation and differentiation into myofibroblasts with release of extracellular matrix proteins $[79,95]$. In addition, the responses of epithelial cells to HRV infections can be modified by the presence of other factors, including cytokines involved in the pathogenesis of allergic asthma [92], e.g. IL-13 and IL-17A. By modifying the cell surface architecture of human tracheal primary epithelial cell cultures, IL-13 enhances the susceptibility to HRV infection [96], while IL-17A enhances the neutrophilic inflammation by altering the chemokine production pattern when examined in primary 


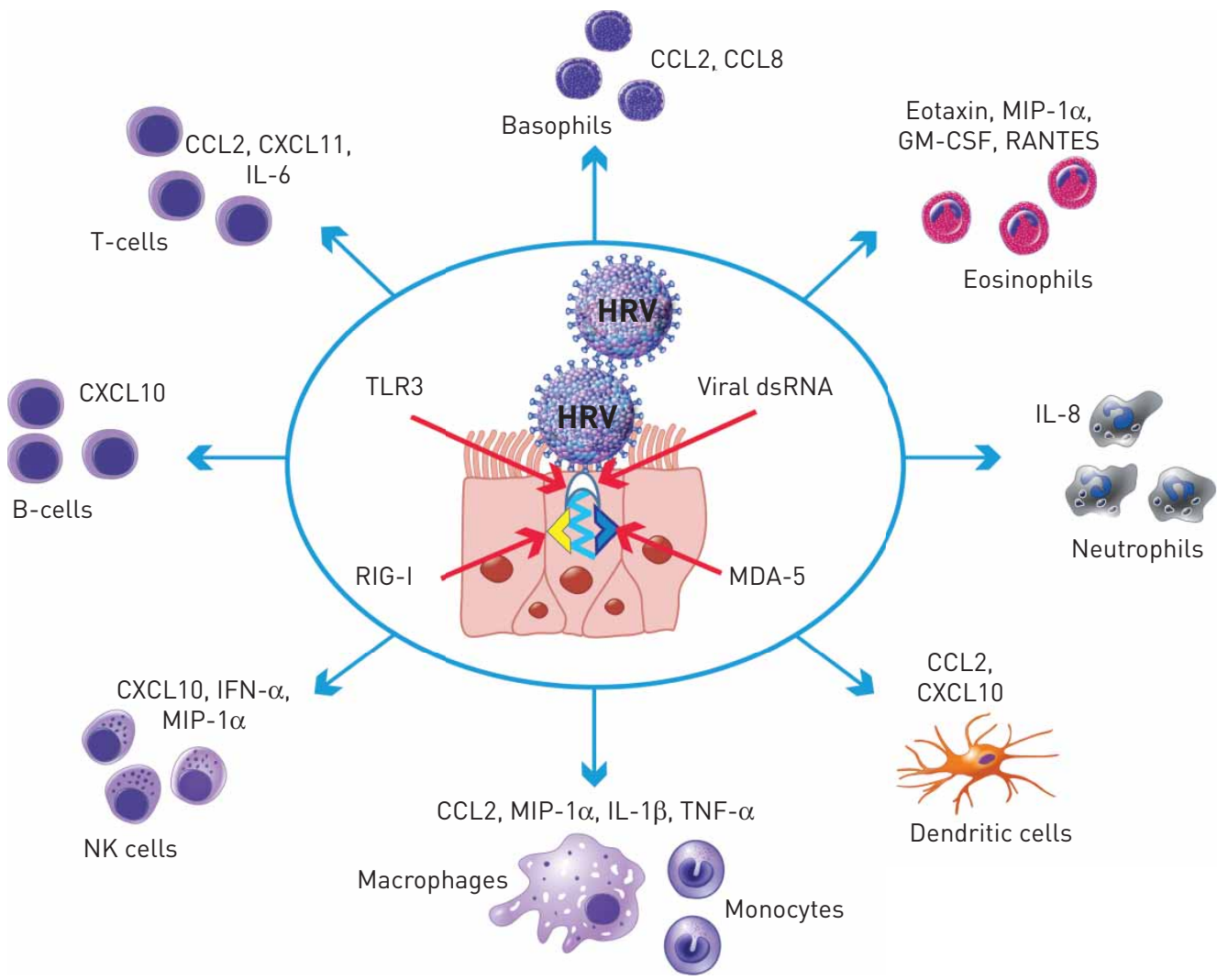

FIGURE 3 Response of airway epithelial cells to human rhinovirus (HRV) infection. HRV double-stranded (ds)RNA is recognised by airway epithelial cells via Toll-like receptor (TLR)-3, which upregulates other pattern recognition receptors, e.g. retinoic acid-inducible gene (RIG)-I and melanoma differentiation-associated gene (MDA)-5. Following infection, airway bronchial epithelial cells produce a variety of cytokines and chemokines that promote recruitment and activation of inflammatory and immuno-effector cells. T- and B-cells, natural killer (NK) cells, macrophages and monocytes, dendritic cells, eosinophils, basophils and neutrophils are shown with their respective chemokines. The inflammatory and immune responses facilitate clearance of the virus but also amplify pre-existing inflammation and contribute to disease exacerbation. IL: interleukin; IFN: interferon; MIP: macrophage inflammatory protein; TNF: tumour necrosis factor; GM-CSF: granulocyte-macrophage colony-stimulating factor; RANTES: regulated on activation, normal T-cells expressed and secreted.

human airway epithelial cell cultures, i.e. increasing the release of the neutrophil chemoattractants (CXCL8) and suppressing the induction of the eosinophil chemoattractant RANTES [97].

\section{Role of HRV in wheezing/asthma inception and exacerbation}

HRVs are well-known causes of upper respiratory tract infections at all ages, occur throughout the year and are the principal cause of LRTI leading to hospitalisation in infants and young children outside of the winter RSV bronchiolitis season [74, 78, 98-105]. While in older children HRVs appear to be the most important viruses in producing exacerbations of asthma $[8,11,81,99]$, there is convincing evidence that they also cause LRTI and precipitate wheezing symptoms in infants and young children $[100,101,106]$. In a study from Finland [102, 103], using PCR-based tests, HRVs were isolated in $33 \%$ of the children hospitalised for wheezing and were the most prevalent respiratory virus identified from $\geqslant 6$ months of age, whereas the most common viral finding at $<6$ months of age was RSV. In the same study, hospitalisation for HRV-induced wheezing in infancy was significantly associated with school-age asthma, with the risk for developing asthma at 6 years of age being more than four-fold higher compared with HRV-negative cases [103]. In addition, compared with RSV patients, children with HRV infections were older and presented more often with atopic dermatitis and blood eosinophilia during acute viral infection, suggesting an association between HRV and allergic sensitisation [104]. Therefore, is it allergic sensitisation that favours HRV infection or does HRV infection favour wheezing/asthma inception and exacerbation? In the large, prospective Childhood Origins of Asthma (COAST) study performed in children at increased risk of developing allergies and asthma, HRV infections were the most common cause of LRTI from birth to 3 years of age $[11,81]$ and represented a significantly increased risk (OR 10) for developing asthma by 6 years of age [11]. The synergistic nature of allergic sensitisation and viral infections in infants relative to 
the onset of obstructive airway diseases was also demonstrated in a clinical study [107], which showed that current wheeze and asthma at 5 years of age were associated with virus-induced acute respiratory illness in children who displayed early allergic sensitisation ( $\geqslant 2$ years of age) but was not observed in nonatopic patients or those sensitised later. Finally, a causal role for allergic sensitisation in favouring or leading to more severe HRV-induced illness is supported by a subsequent evaluation of the COAST study, showing that allergic sensitisation may precede HRV-associated wheezing and may lead to an increased risk of wheezing illness caused by HRV but not RSV [108], while neither HRV- nor RSV-induced wheeze increase the risk of subsequent allergic sensitisation [10, 105-108]. In agreement with these epidemiological data are the results of a study comparing the immune responses during acute asthma exacerbation and convalescence in children sensitised to house dust mite (HDM). It was shown that IgE anti-HDM titres declined during convalescence and fell more rapidly in virus-infected subjects compared to subjects with acute asthma exacerbation not due to viral infection [109]. All these observations have led to the notion that rather than play a role in the induction and progression of allergy in asthma, HRV infections in early life may be favoured by the presence or the predisposition to develop allergic sensitisation, at least in genetically susceptible individuals.

\section{Allergic sensitisation, asthma and HRV infection}

One hypothesis that may explain why HRV infection may be favoured by allergic sensitisation is that the Th2 bias, which is the characteristic of the immune responses against allergens in atopic individuals, may modify the host antimicrobial defences and thus attenuate the ability to fight viral infections via immune deviation (fig. 4) [110]. Hence the nature of immune responses to HRV differs between atopic asthmatic and normal subjects, which is characterised by a deficient production of IFN- $\gamma$ and IL-12 by PBMC in atopic asthmatics [111]. Using PBMC-derived plasmacytoid dendritic cells it was further shown that: 1) the surface expression of the high-affinity IgE receptor FceRI was higher in allergic asthmatic children, compared with nonallergic nonasthmatic controls; 2) IFN- $\alpha$ and IFN- $\lambda 1$ production in response to HRV was inversely associated with the intensity of the FceRI expression on plasmacytoid dendritic cells; and 3) after FceRI cross-linking with rabbit anti-human IgE, allergic asthmatic children had significantly lower HRV-induced IFN responses than allergic nonasthmatic controls [112]. Moreover, in vitro exposure of

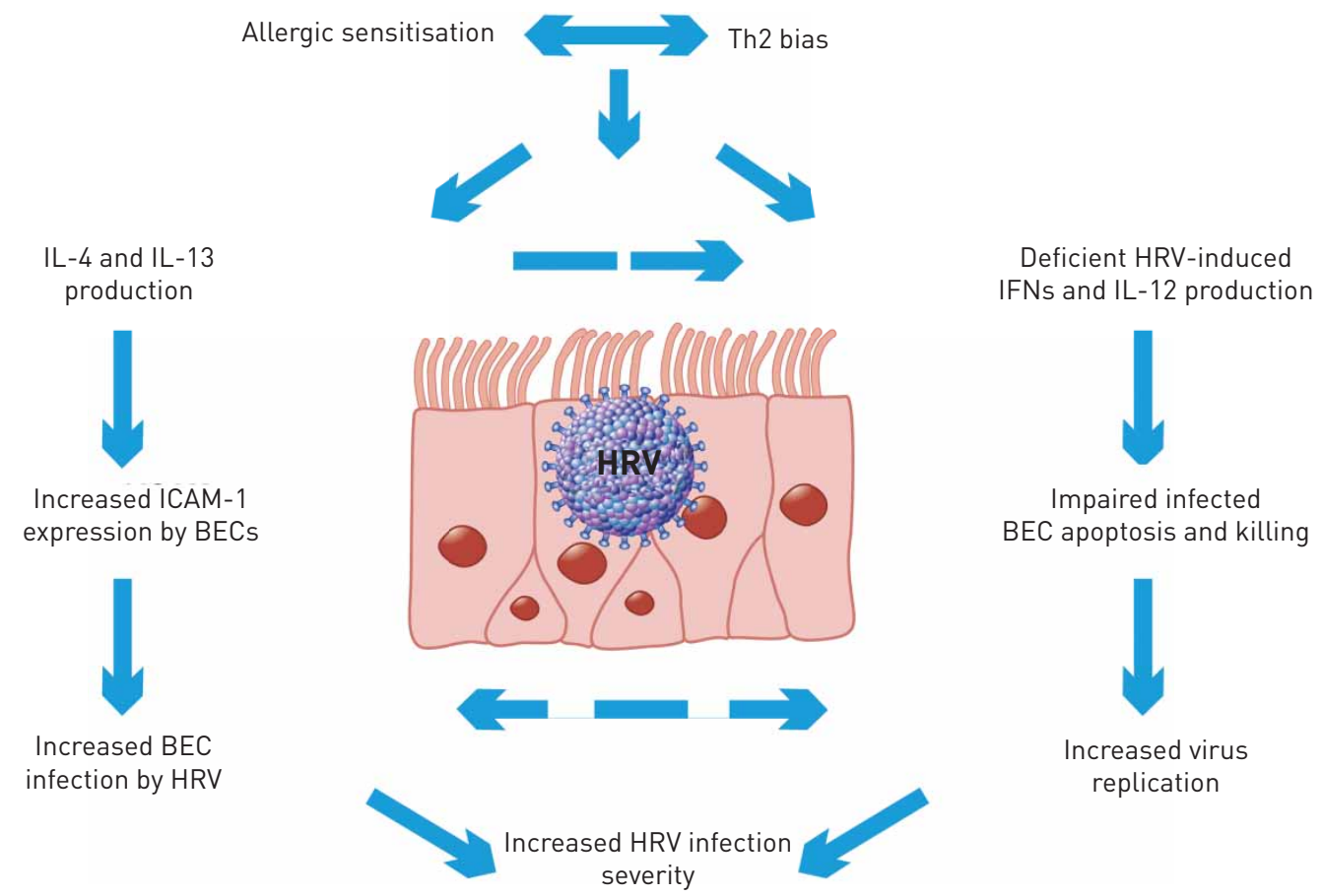

FIGURE 4 Factors favouring human rhinovirus (HRV) infection severity in allergic individuals. The host reaction to HRV in atopic asthmatic subjects is characterised by a T-helper (Th)2-type immune response with increased synthesis and release of cytokines, such as interleukin (IL)-4, IL-5, IL-10 and IL-13, which are capable of increasing the expression of intercellular adhesion molecule (ICAM)-1, the major HRV receptor, on the surface of bronchial epithelial cells (BECs). This probably renders the cells more susceptible to infection. BECs from atopic asthmatics also produce reduced levels of IL-12 and interferon (IFN)- $\alpha$, IFN- $\gamma$ and IFN- $\lambda$, cytokines involved in limiting viral replication. This impairs infected BEC apoptosis and increases HRV infection severity. 
human BECs to HRV revealed that under the influence of an atopic environment the inflammatory response to the virus was downregulated, viral proliferation was increased and virus-induced cell damage was augmented [110]. A deficient innate immune response to HRV infection was demonstrated on atopic asthmatic BEC primary cultures that were characterised by a profound impairment of virus-induced IFN- $\beta$ production, impaired epithelial cell apoptosis and increased virus replication [113]. Deficient in vitro induction of IFN- $\lambda$ by HRV infection in asthmatic primary BECs and alveolar macrophages was also reported, which was strongly associated with high HRV replication in vitro [114]. This deficient in vitro IFN- $\lambda$ production was also highly correlated with the severity of HRV-induced asthma exacerbation and virus load when atopic asthmatics and normal volunteers were experimentally inoculated with HRV serotype 16 [114]. Whether a pan-defect in immune response in atopic subjects is specific or more pronounced for HRV or may also be observed with other viruses has not yet been defined [115]. Th2-type cytokines may also favour HRV infection by increasing the expression of ICAM-1, the receptor they bind to at the surface of epithelial cells in the respiratory tract. IL-4, IL-5, IL-10 and IL-13 induce a $2.7-$ to 5.1-fold enhancement of ICAM-1 expression by uninfected immortalised cell lines and primary human BECs and cause a further two-fold increase in infected cells over the expression induced by HRV infection by itself [116-118]. Besides being a major receptor for HRV, ICAM-1 also interacts physiologically with leukocyte function-associated antigen-1, an adhesion molecule expressed on polymorphonuclear leukocytes, which plays a vital role in the recruitment, migration and activation of immune effector cells to sites of local inflammation. We are therefore facing a vicious circle in which allergic sensitisation upregulates the expression of ICAM-1, the site of attachment for $90 \%$ of HRV serotypes [15, 16], facilitating viral cell attachment and entry, while HRV infection further enhances ICAM-1 expression, amplifying the inflammatory response to allergens [117, 118]. Finally, exposure to HRV might alter the expression levels of one or more gene that may increase susceptibility to the development of asthma. The first genome-wide association study of childhood-onset asthma revealed a susceptibility locus on chromosome 17q21 [119]. Variation at the 17q21 locus is known to be primarily associated with childhood-onset asthma but not with atopy [120], and the effects on asthma are larger in children with reported respiratory infections in infancy [121]. The disease-associated variants at this locus are associated with expression levels of two 17q21 genes, GSDMB and ORMDL3 [122]. Interestingly, ÇALIŞKAN et al. [123] have recently demonstrated that the 17q21 variants were associated with HRV wheezing illnesses in early life but not with RSV wheezing illnesses, and that the expression levels of GSDMB and of ORMDL3 were significantly increased in HRV-stimulated PBMCs, compared with unstimulated PBMCs. However, as partially recognised by the authors, there are some limitations of this study. 1) HRV is the most common virus encountered in viral wheeze in childhood and it is not possible to exclude that the absence of an observed interaction with RSV could be due to insufficient power. 2) The ability of RSV to modify the expression levels of ORMDL3 and GSDMB in PBMCs was not tested. 3) The causality between HRV viral exposure and wheezing illness in children was not established, and it may well be that HRV wheezing illness is not causal but merely a marker of the underlying predisposition for asthma and a trigger in predisposed children.

\section{Rhinovirus infection and asthma induction}

Despite strong epidemiological and experimental support for an important role for HRV in the pathogenesis of lower airways disease characterised by bronchial hyperreactivity and airflow limitation, the mechanism of this effect remains unexplained. Whether viral infections alone are sufficient or additional cofactors or individual predisposition are required to initiate wheezing and acute asthma attacks remains unresolved. Airway changes, suggesting inflammation, are not consistently demonstrated in normal subjects after direct exposure to HRV [124]. This may be explained on the basis of the varying pathogenicity of different HRV serotypes and the different doses of the inoculum used in the different settings [125]. Experimental exposure to HRV in humans does not usually provoke acute asthma symptoms [126], but may increase bronchial reactivity in asthmatic [127] and atopic subjects [128]. During an experimentally induced upper respiratory tract infection by HRV serotype 16, cold symptoms were accompanied by an increased responsiveness to histamine in both asthmatics and normal subjects [85]. In the same report, bronchial biopsies obtained during the symptomatic phase showed an increase in eosinophil numbers in the epithelium, which appeared to persist in the asthmatic group but not in the normal subject group [85]. CHeUng et al. [129] studied the effects of experimental infection with inhaled wild-type HRV serotype 16 on the maximal degree of airway narrowing in response to methacholine in patients with mild-to-moderate asthma. Only 2 days after HRV serotype 16 inoculation, the authors demonstrated increased airway hyperresponsiveness that augmented at days 7 and 15, and correlated with worsening of the asthma symptom score [129]. Experimental inoculation of HRV serotype 16 in volunteers with respiratory allergy also increases airway hyperresponsiveness to inhaled histamine [130] and, similar to the observation for methacholine, the change in histamine response caused by rhinovirus infection seems to be more significant in allergic subjects compared with non-allergic control subjects [131]. These data further 
support the concept that the presence of atopy may contribute to increased lower airway effects of rhinovirus infection. Also, in childhood atopy may favour a prolonged airway hyperresponsiveness after $\mathrm{HRV}$-induced upper respiratory tract infections, since atopic children tend to experience more symptoms related to colds leading to asthma exacerbations than non-atopic children [132].

Proposed mechanisms that can explain why HRV infections may increase bronchial reactivity include impairment in airway barrier function through physical injury. Confocal microscopy and immunoblotting revealed the loss of tight junction complexes in HRV-infected primary human airway epithelial cells grown at air-liquid interface [133]. This observation was associated with increased paracellular permeability, effects that appear to be related to viral replication in immortalised cell lines grown as polarised monolayers [133], but may be amplified by pro-inflammatory cytokines [134]. In experimental and naturally occurring HRV-induced infection, airway epithelial cell and inflammatory-immune effector cell activation has been described with cytokines, chemokines and growth factor production associated with increased release of histamine and eosinophil cationic protein [135-139]. Recruitment of neutrophils, eosinophils, mast cells and $\mathrm{CD}^{+}$and $\mathrm{CD}^{+}$T-cells has been demonstrated through increased release of IL-6, IL-8, IL-16, IFN- $\gamma$-induced protein-10, eotaxin, RANTES, leukotrienes and other pro-inflammatory cytokines [137, 140, 141]. The production of these and other pro-inflammatory cytokines can lead to airway damage, neutrophilic inflammation remodelling, mucus hypersecretion and bronchial hyperresponsiveness [142].

\section{Conclusions}

In summary, two separate prototypes of viral-induced respiratory infections in childhood that represent different pathogenetic mechanisms are provoked by RSV and by HRV (fig. 5). RSV is cytopathic for the airway epithelium of the growing lung. It is predominant in bronchiolitis in young infants during the winter months, with an overall prevalence that alternates with the varying severity of annual epidemics but may represent up to $80 \%$ in infants aged $<3$ months, with a rapid decrease thereafter. The primary infection usually causes a severe illness, especially in infants with no RSV-specific immunity, whereas subsequent infections usually cause milder symptoms. RSV-induced LRTI in early childhood is associated with subsequent bronchial obstructive episodes and reversible lower lung function up to 11 years of age. This association is not caused by an increased risk of allergic sensitisation but rather linked to neuromuscular tone instability.

In contrast to RSV, infections with HRVs have been shown to occur throughout the year, affect people of all ages and induce minimal cytotoxicity, but stimulate the release of mediators by structural and

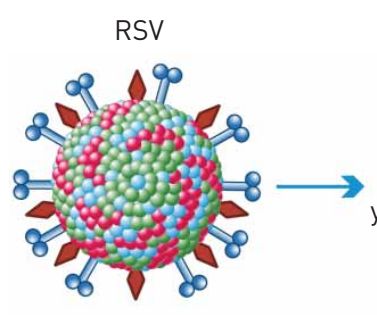

More inducer than trigger

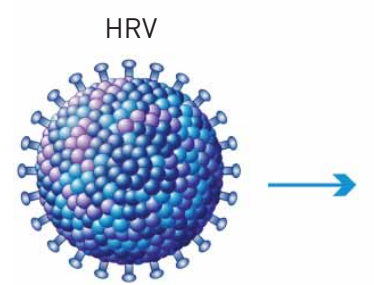

More trigger than inducer

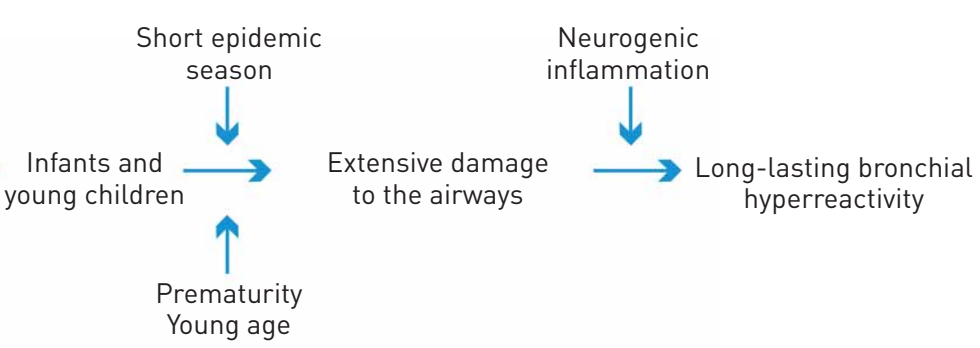

Infants, children and adolescents

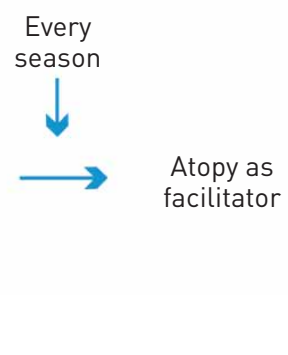

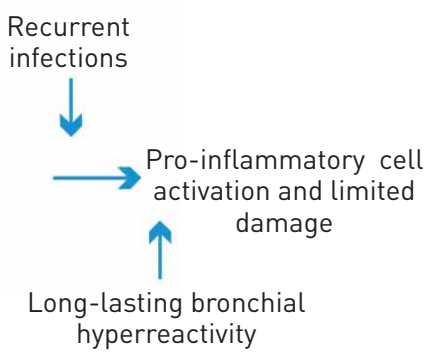

FIGURE 5 The two different prototypes of viral-induced respiratory infections. Respiratory syncytial virus (RSV) is the predominant aetiological agent of lower respiratory tract infections in young infants, but has a short epidemic season. Risk factors for developing severe infection are prematurity and young chronological age. The infection is associated with extensive airway epithelial damage and upregulation of neurogenic inflammation, leading to long-lasting bronchial hyperreactivity. Human rhinovirus (HRV) infection, which may affect infants, children and adolescents, occurs every season. It is facilitated by atopy and induces recurrent infections characterised by minimal cytotoxicity, but stimulates the release of mediators by structural and inflammatory cells in the airways and also induces long-lasting bronchial hyperreactivity. 
inflammatory cells in the airways. HRV diagnosis relies almost entirely on PCR because this virus is difficult to culture, there are no antigen detection tests available and serology is not feasible. The interpretation of positive PCR results has been made difficult by high virus detection rates in asymptomatic subjects (up to $40-68 \%$ in young children) and, in particular, by multiple coexisting viruses in symptomatic subjects (up to 43\%). The susceptibility to HRV-induced bronchiolitis and wheezing seems to be linked to predisposition since it is often associated with atopic dermatitis, blood eosinophilia and family history of asthma/atopy.

RSV seems to act as an "inducer" rather than "trigger", it mainly affects infants and young children during a short epidemic seasons. Prematurity and young age are strong risk factors to developing severe lower respiratory tract symptoms. The infection is characterised morphologically by extensive damage to the airway structures and induction of a neurogenic inflammation; with the latter assumed to be responsible for long-lasting bronchial hyperreactivity.

HRVs seem to act as a "trigger" rather than an "inducer", affecting infants, children and adolescents, but also adults. These viruses are extremely widespread, continuously co-circulate during all seasons and recognise atopy as a facilitating factor. HRVs induce recurrent infection characterised by limited, if any, cytotoxicity but rather by airway cell activation with release of pro-inflammatory mediators leading to recurrent or persistent bronchial hyperreactivity in predisposed individuals. Significant gaps remain in our current knowledge regarding the role of respiratory RSV and HRV infections in the inception and exacerbation of asthma and the complex interactions among the viral, host and developmental stage of affected individuals, and environmental factors.

Future directions of study need to focus on the following. 1) Characterisation of the different innate epithelial responses to RSV and HRV and their interaction with the adaptive immune reactions during the primary and subsequent infections. 2) Characterisation of the effects of different conditions and cofactors, such as chronologic age at the first RSV and HRV infections and the effect of allergic predisposition and sensitisation on infectious outcomes. 3) Identification of new genes associated with RSV and HRV pathogenesis, while solidifying previously reported associations.

New rodent models of RSV and HRV infections, advances in microarray, other high-throughput technologies and genome-wide association studies should offer the tools for future research. Ultimately, the aim of these efforts is to provide the means for more effective approaches for prevention and early and effective therapies of the first RSV- and HRV-induced infections, with the hope of modifying subsequent wheezing illnesses.

\section{References}

1 Global Initiativefor Asthma. Global Strategy for Asthma Management and Prevention. Revised 2014. www. ginasthma.org/local/uploads/files/GINA_Report_2014_Aug12.pdf Date last updated: December 2012. Date last accessed: October 3, 2013.

2 Duijts L. Fetal and infant origins of asthma. Eur J Epidemiol 2012; 27: 5-14.

3 Le Souëf PN. Gene-environmental interaction in the development of atopic asthma: new developments. Curr Opin Allergy Clin Immunol 2009; 9: 123-127.

4 von Mutius E. Environmental factors influencing the development and progression of pediatric asthma. $J$ Allergy Clin Immunol 2002; 109 Suppl. 6: S525-S532.

5 Regamey N, Kaiser L, Roiha HL, et al. Viral etiology of acute respiratory infections with cough in infancy: a community-based birth cohort study. Pediatr Infect Dis J 2008; 27: 100-105.

6 Kusel MM, de Klerk NH, Holt PG, et al. Role of respiratory viruses in acute upper and lower respiratory tract illness in the first year of life: a birth cohort study. Pediatr Infect Dis J 2006; 25: 680-686.

7 Kocevar VS, Bisgaard H, Jonsson L, et al. Variations in pediatric asthma hospitalization rates and costs between and within Nordic countries. Chest 2004; 125: 1680-1684.

8 Jackson DJ, Lemanske RF Jr. The role of respiratory virus infections in childhood asthma inception. Immunol Allergy Clin North Am 2010; 30: 513-522.

9 Stein RT, Sherrill D, Morgan WJ, et al. Respiratory syncytial virus in early life and risk of wheeze and allergy by age 13 years. Lancet 1999; 354: 541-545.

10 Henderson J, Hilliard TN, Sherriff A, et al. Hospitalization for RSV bronchiolitis before 12 months of age and subsequent asthma, atopy and wheeze: a longitudinal birth cohort study. Pediatr Allergy Immunol 2005; 16: 386-392.

11 Jackson DJ, Gangnon RE, Evans MD, et al. Wheezing rhinovirus illnesses in early life predict asthma development in high-risk children. Am J Respir Crit Care Med 2008; 178: 667-672.

12 Gern JE, Busse WW. Relationship of viral infections to wheezing illnesses and asthma. Nat Rev Immunol 2002; 2 : $132-138$.

13 Koponen P, Helminen M, Paassilta M, et al. Preschool asthma after bronchiolitis in infancy. Eur Respir J 2012; 39: 76-80.

14 Tortorolo L, Langer A, Polidori G, et al. Neurotrophin overexpression in lower airways of infants with respiratory syncytial virus infection. Am J Respir Crit Care Med 2005; 172: 233-237.

15 Martinez FD, Wright AL, Taussig LM, et al. Asthma and wheezing in the first six years of life. $N$ Engl J Med 1995; 332: 133-138. 
Sigurs N, Bjarnason R, Sigurbergsson F, et al. Respiratory syncytial virus bronchiolitis in infancy is an important risk factor for asthma and allergy at age 7. Am J Respir Crit Care Med 2000; 161: 1501-1507.

17 Wennergren G, Kristjansson S. Relationship between respiratory syncytial virus bronchiolitis and future obstructive airway diseases. Eur Respir J 2001; 18: 1044-1058.

18 Johnston SL, Pattemore PK, Sanderson G, et al. Community study of role of viral infections in exacerbations of asthma in 9-11 year old children. BMJ 1995; 310: 1225-1228.

19 Busse W, Gern J. Viruses in asthma. J Allergy Clin Immunol 1997; 100: 147-150.

20 Rakes GP, Arruda E, Ingram JM, et al. Rhinovirus and respiratory syncytial virus in wheezing children requiring emergency care. Am J Respir Crit Care Med 1999; 159: 785-790.

21 Heymann PW, Carper HT, Murphy DD, et al. Viral infections in relation to age, atopy, and season of admission among children hospitalized for wheezing. J Allergy Clin Immunol 2004; 114: 239-247.

22 Blanken MO, Rovers MM, Molenaar JM, et al. Respiratory syncytial virus and recurrent wheeze in healthy preterm infants. N Engl J Med 2013; 368: 1791-1799.

23 Malhotra $\mathrm{R}$, Ward $\mathrm{M}$, Bright $\mathrm{H}$, et al. Isolation and characterisation of potential respiratory syncytial virus receptor(s) on epithelial cells. Microbes Infect 2003; 5: 123-133.

24 Jansen RR, Wieringa J, Koekkoek SM, et al. Frequent detection of respiratory viruses without symptoms: toward defining clinically relevant cutoff values. J Clin Microbiol 2011; 49: 2631-2636.

25 Kumar S, Wang L, Fan J, et al. Detection of 11 common viral and bacterial pathogens causing community-acquired pneumonia or sepsis in asymptomatic patients by using a multiplex reverse transcription-PCR assay with manual (enzyme hybridization) or automated (electronic microarray) detection. J Clin Microbiol 2008; 46: 3063-3072.

26 Medici MC, Arcangeletti MC, Rossi GA, et al. Four year incidence of respiratory syncytial virus infection in infants and young children referred to emergency departments for lower respiratory tract diseases in Italy: the “Osservatorio VRS” Study (2000-2004). New Microbiol 2006; 29: 35-43.

27 Lanari M, Giovannini M, Giuffrè L, et al. Prevalence of respiratory syncytial virus infection in Italian infants hospitalized for acute lower respiratory tract infections, and association between respiratory syncytial virus infection risk factors and disease severity. Pediatr Pulmonol 2002; 33: 458-465.

28 Hall CB, Weinberg GA, Iwane MK, et al. The burden of respiratory syncytial virus infection in young children. $N$ Engl J Med 2009; 360: 588-598.

29 Simoes EA. Environmental and demographic risk factors for respiratory syncytial virus lower respiratory tract disease. J Pediatr 2003; 143 Suppl. 5: S118-S126.

30 Rossi GA, Medici MC, Arcangeletti MC, et al. Risk factors for severe RSV-induced lower respiratory tract infection over four consecutive epidemics. Eur I Pediatr 2007; 166: 1267-1272.

31 Murphy BR, Alling DW, Snyder MH, et al. Effect of age and pre-existing antibody on serum antibody response of infants and childrent to the $\mathrm{F}$ and $\mathrm{G}$ glycoproteins during respiratory syncytial virus infection. J Clin Microbiol 1986; 24: 894-898.

32 Delgado MF, Coviello S, Monsalvo AC, et al. Lack of antibody affinity maturation due to poor Toll-like receptor stimulation leads to enhanced respiratory syncytial virus disease. Nat Med 2009; 15: 34-41.

33 Yamazaki H, Tsutsumi H, Matsuda K, et al. Effect of maternal antibody on IgA antibody response in nasopharyngeal secretion in infants and children during primary respiratory syncytial virus infection. J Gen Virol 1994; 75: 2115-2119.

34 Scagnolari C, Midulla F, Selvaggi C, et al. Evaluation of viral load in infants hospitalized with bronchiolitis caused by respiratory syncytial virus. Med Microbiol Immunol 2012; 201: 311-317.

35 Tregoning JS, Schwarze J. Respiratory viral infections in infants: causes, clinical symptoms, virology, and immunology. Clin Microbiol Rev 2010; 23: 74-98.

36 Fonceca AM, Flanagan BF, Trinick R, et al. Primary airway epithelial cultures from children are highly permissive to respiratory syncytial virus infection. Thorax 2012; 67: 42-48.

37 Guo-Parke H, Canning P, Douglas I, et al. Relative respiratory syncytial virus cytopathogenesis in upper and lower respiratory tract epithelium. Am J Respir Crit Care Med 2013; 188: 842-851.

38 McNamara PS, Flanagan BF, Selby AM, et al. Pro- and anti-inflammatory responses in respiratory syncytial virus bronchiolitis. Eur Respir J 2004; 23: 106-112.

39 Openshaw PJ, Tregoning JS. Immune responses and disease enhancement during respiratory syncytial virus infection. Clin Microbiol Rev 2005; 18: 541-555.

40 Lifland AW, Jung J, Alomas E, et al. Human respiratory syncytial virus nucleoprotein and inclusion bodies antagonize the innate immune response mediated by MDA5 and MAVS. J Virol 2012; 86: 8245-8258.

41 Shingai M, Azuma M, Ebihara T, et al. Soluble G protein of respiratory syncytial virus inhibits Toll-like receptor 3/4-mediated IFN- $\beta$ induction. Int Immunol 2008; 20: 1169-1180.

42 Swedan S, Musiyenko A, Barik S. Respiratory syncytial virus nonstructural proteins decrease levels of multiple members of the cellular interferon pathways. J Virol 2009; 83: 9682-9693.

43 Kauvar LM, Harcourt JL, Haynes LM, et al. Therapeutic targeting of respiratory syncytial virus G-protein. Immunotherapy 2010; 2: 655-661

44 Bukreyev A, Yang L, Fricke J, et al. The secreted form of respiratory syncytial virus G glycoprotein helps the virus evade antibody-mediated restriction of replication by acting as an antigen decoy and through effects on Fc receptor-bearing leukocytes. I Virol 2008; 82: 12191-12204.

45 Legg JP, Hussain IR, Warner JA, et al. Type 1 and type 2 cytokine imbalance in acute respiratory syncytial virus bronchiolitis. Am J Respir Crit Care Med 2003; 168: 633-639.

46 Kristjansson S, Bjarnarson SP, Wennergren G, et al. Respiratory syncytial virus and other respiratory viruses during the first 3 months of life promote a local TH2-like response. J Allergy Clin Immunol 2005; 116: 805-811.

47 Aberle JH, Aberle SW, Dworzak MN, et al. Reduced interferon- $\gamma$ expression in peripheral blood mononuclear cells of infants with severe respiratory-syncytial virus disease. Am J Respir Crit Care Med 1999; 160: 1263-1268.

48 Tang ML, Kemp AS, Thorburn J, et al. Reduced interferon- $\gamma$ secretion in neonates and subsequent atopy. Lancet 1994; 344: 983-985.

49 Gold DR, Bloomberg GR, Cruikshank WW, et al. Parental characteristics, somatic fetal growth, and season of birth influence innate and adaptive cord blood cytokine responses. J Allergy Clin Immunol 2009; 124: 1078-1087. 
Copenhaver CC, Gern JE, Li Z, et al. Cytokine response patterns, exposure to viruses, and respiratory infections in the first year of life. Am J Respir Crit Care Med 2004; 170: 175-180.

McNamara PS, Flanagan BF, Hart CA, et al. Production of chemokines in the lungs of infants with severe respiratory syncytial virus bronchiolitis. J Infect Dis 2005; 191: 1225-1232.

Becker Y. Respiratory syncytial virus (RSV) evades the human adaptive immune system by skewing the Th1/Th2 cytokine balance toward increased levels of Th2 cytokines and IgE, markers of allergy - a review. Virus Genes 2006; 33: 235-252.

Shirey KA, Pletneva LM, Puche AC, et al. Control of RSV-induced lung injury by alternatively activated macrophages is IL-4R $\alpha$-, TLR4-, and IFN- $\beta$-dependent. Mucosal Immunol 2010; 3: 291-300. Opal SM, DePalo VA. Anti-inflammatory cytokines. Chest 2000; 117: 1162-1172.

Hornsleth A, Loland L, Larsen LB. Cytokines and chemokines in respiratory secretion and severity of disease in infants with respiratory syncytial virus (RSV) infection. J Clin Virol 2001; 21: 163-170.

Bont L, Heijnen CJ, Kavelaars A, et al. Monocyte IL-10 production during respiratory syncytial virus bronchiolitis is associated with recurrent wheezing in a one-year follow-up study. Am J Respir Crit Care Med 2000; 161: 1518-1523.

Sigurs N, Aljassim F, Kjellman B, et al. Asthma and allergy patterns over 18 years after severe RSV bronchiolitis in the first year of life. Thorax 2010; 65: 1045-1052.

Bont L, Ramilo O. The relationship between RSV bronchiolitis and recurrent wheeze: the chicken and the egg. Early Hum Dev 2011; 87 Suppl. 1: S51-S54.

Weinmayr G, Genuneit J, Nagel G, et al. International variations in associations of allergic markers and diseases in children: ISAAC Phase Two. Allergy 2010; 65: 766-775.

Simões EA, Carbonell-Estrany $\mathrm{X}$, Rieger $\mathrm{CH}$, et al. The effect of respiratory syncytial virus on subsequent recurrent wheezing in atopic and nonatopic children. J Allergy Clin Immunol 2010; 126: 256-262.

Piedimonte G. Neural mechanisms of respiratory syncytial virus-induced inflammation and prevention of respiratory syncytial virus sequelae. Am J Respir Crit Care Med 2001; 163: S18-S21.

Hu C, Wedde-Beer K, Auais A, et al. Nerve growth factor and nerve growth factor receptors in respiratory syncytial virus-infected lungs. Am J Physiol Lung Cell Mol Physiol 2002; 283: L494-L502. Levi-Montalcini R. The nerve growth factor 35 years later. Science 1987; 237: 1154-1162.

Bonini S, Lambiase A, Angelucci F, et al. Circulating nerve growth factor levels are increased in humans with allergic diseases and asthma. Proc Natl Acad Sci USA 1996; 93: 10955-10960.

Wright M, Piedimonte G. Respiratory syncytial virus prevention and therapy: past, present, and future. Pediatr Pulmonol 2011; 46: 324-347.

Nilsson G, Forsberg-Nilsson K, Xiang Z, et al. Human mast cells express functional TrkA and are a source of nerve growth factor. Eur J Immunol 1997; 27: 2295-2301.

Ehrhard PB, Erb P, Graumann U, et al. Expression of nerve growth factor and nerve growth factor receptor tyrosine kinase Trk in activated CD4-positive T-cell clones. Proc Natl Acad Sci USA 1993; 90: 10984-10988. Gern JE. The ABCs of rhinoviruses, wheezing, and asthma. J Virol 2010; 84: 7418-7426.

Vlasak M, Blomqvist S, Hovi T, et al. Sequence and structure of human rhinoviruses reveal the basis of receptor discrimination. J Virol 2003; 77: 6923-6930.

McErlean P, Shackelton LA, Andrews E, et al. Distinguishing molecular features and clinical characteristics of a putative new rhinovirus species, human rhinovirus C (HRV C). PloS one 2008; 3: e1847.

Crotty S, Andino R. Implications of high RNA virus mutation rates: lethal mutagenesis and the antiviral drug ribavirin. Microbes Infect 2002; 4: 1301-1307.

Gern JE, Galagan DM, Jarjour NN, et al. Detection of rhinovirus RNA in lower airway cells during experimentally induced infection. Am J Respir Crit Care Med 1997; 155: 1159-1161.

Malmström K, Pitkaranta A, Carpen $\mathrm{O}$, et al. Human rhinovirus in bronchial epithelium of infants with recurrent respiratory symptoms. J Allergy Clin Immunol 2006; 118: 591-596. symptomatic and asymptomatic infections. J Infect Dis 2008; 197: 382-389. responses in the first year of life. J Allergy Clin Immunol 2006; 117: 72-78.

Miller EK, Bugna J, Libster R, et al. Human rhinoviruses in severe respiratory disease in very low birth weight infants. Pediatrics 2012; 129: e60-e67.

van der Zalm MM, Wilbrink B, van Ewijk BE, et al. Highly frequent infections with human rhinovirus in healthy young children: a longitudinal cohort study. J Clin Virol 2011; 52: 317-320.

Rollinger JM, Schmidtke M. The human rhinovirus: human-pathological impact, mechanisms of antirhinoviral agents, and strategies for their discovery. Med Res Rev 2011; 31: 42-92.

Lee WM, Lemanske FR Jr, Evans MD, et al. Human rhinovirus species and season of infection determine illness severity. Am J Respir Crit Care Med 2012; 186: 886-891.

Kieninger E, Fuchs O, Latzin P, et al. Rhinovirus infections in infancy and early childhood. Eur Respir J 2013; 41 : $443-452$.

Lemanske RF Jr, Jackson DJ, Gangnon RE, et al. Rhinovirus illnesses during infancy predict subsequent childhood wheezing. J Allergy Clin Immunol 2005; 116: 571-575.

Nicholson KG, Kent J, Ireland DC. Respiratory viruses and exacerbations of asthma in adults. Br Med J 1993, 307: 982-986. asymptomatic infants. Pediatr Allergy Immunol 2003; 14: 363-370.

Van Gageldonk-Lafeber AB, Heijnen ML, Bartelds AI, et al. A case-control study of acute respiratory tract infection in general practice patients in The Netherlands. Clin Infect Dis 2005; 41: 490-497.

Fraenkel DJ, Bardin PG, Sanderson G, et al. Lower airways inflammation during rhinovirus colds in normal and in asthmatic subjects. Am J Respir Crit Care Med 1995; 151: 879-886.

Gern JE, French DA, Grindle KA, et al. Double-stranded RNA induces the synthesis of specific chemokines by bronchial epithelial cells. Am J Respir Cell Mol Biol 2003; 28: 731-737. 
Winther B, Gwaltney JM Jr, Hendley JO. Respiratory virus infection of monolayer cultures of human nasal epithelial cells. Am Rev Respir Dis 1990; 141: 839-845.

Bossios A, Psarras S, Gourgiotis D, et al. Rhinovirus infection induces cytotoxicity and delays wound healing in bronchial epithelial cells. Respir Res 2005; 6: 114-125.

Papadopoulos NG, Bates PJ, Bardin PG, et al. Rhinoviruses infect the lower airways. J Infect Dis 2000; 181: 1875-1884.

Winther B, Gwaltney JM Jr, Mygind N, et al. Sites of rhinovirus recovery after point inoculation of the upper airway. JAMA 1986; 256: 1763-1767.

Sanders SP, Siekierski ES, Porter JD, et al. Nitric oxide inhibits rhinovirus-induced cytokine production and viral replication in a human respiratory epithelial cell line. J Virol 1998; 72: 934-942.

Message SD, Johnston SL. Host defense function of the airway epithelium in health and disease: clinical background. J Leukoc Biol 2004; 75: 5-17.

Slater L, Bartlett NW, Haas JJ, et al. Co-ordinated role of TLR-3, RIG-I and MDA5 in the innate response to rhinovirus in bronchial epithelium. PLoS Pathog 2010; 6: e1001178.

Turner RB, Weingand KW, Yeh $\mathrm{CH}$, et al. Association between interleukin-8 concentration in nasal secretions and severity of symptoms of experimental rhinovirus colds. Clin Infect Dis 1998; 26: 840-846.

Skevaki CL, Psarras S, Volonaki E, et al. Rhinovirus-induced basic fibroblast growth factor release mediates airway remodeling features. Clin Transl Allergy 2012; 2: 14

Lachowicz-Scroggins ME, Boushey HA, Finkbeiner WE, et al. Interleukin-13 induced mucous metaplasia increases susceptibility of human airway epithelium to rhinovirus infection. Am J Respir Cell Mol Biol 2010; 43: 652-661

Wiehler S, Proud D. Interleukin-17A modulates human airway epithelial responses to human rhinovirus infection. Am J Physiol Cell Mol Physiol 2007; 293: L505-L515.

Hayden FG. Rhinovirus and the lower respiratory tract. Rev Med Virol 2004; 14: 17-31.

Montalbano MM, Lemanske RF Jr. Infections and asthma in children. Curr Opin Pediatr 2002; 14: 334-347.

Aya Takeyama A, Hashimoto K, Sato M, et al. Clinical and epidemiologic factors related to subsequent wheezing after virus-induced lower respiratory tract infections in hospitalized pediatric patients younger than 3 years. Eur J Pediatr 2014; 173: 959-966.

Miller EK, Lu X, Erdman DD, et al. Rhinovirus-associated hospitalizations in young children. J Infect Dis 2007; 195: 773-781.

Jartti T, Korppi M. Rhinovirus-induced bronchiolitis and asthma development. Pediatr Allergy Immunol 2011; 22: $350-355$

Kotaniemi-Syrjänen A, Vainionpää R, Reijonen TM, et al. Rhinovirus-induced wheezing in infancy the first sign of childhood asthma?. J Allergy Clin Immunol 2003; 111: 66-71.

Korppi M, Kotaniemi-Syrjänen A, Waris M, et al. Rhinovirus-associated wheezing in infancy: comparison with respiratory syncytial virus bronchiolitis. Pediatr Infect Dis J 2004; 23: 995-999.

Gavala ML, Bertics PJ, Gern JE. Rhinoviruses, allergic inflammation, and asthma. Immunol Rev 2011; 242: 69-90. van der Gugten AC, van der Zalm MM, Uiterwaal CS, et al. Human rhinovirus and wheezing: short and long-term associations in children. Pediatr Infect Dis J 2013; 32: 827-833.

Kusel MM, de Klerk NH, Kebadze T, et al. Early-life respiratory viral infections, atopic sensitization, and risk of subsequent development of persistent asthma. J Allergy Clin Immunol 2007; 119: 1105-1110.

Jackson DJ, Evans MD, Gangnon RE, et al. Evidence for a causal relationship between allergic sensitization and rhinovirus wheezing in early life. Am J Respir Crit Care Med 2012; 185: 281-285.

Hales BJ, Martin AC, Pearce LJ, et al. Anti-bacterial IgE in the antibody responses of house dust mite allergic children convalescent from asthma exacerbation. Clin Exp Allergy 2009; 39: 1170-1178.

Xatzipsalti M, Psarros F, Konstantinou G, et al. Modulation of the epithelial inflammatory response to rhinovirus in an atopic environment. Clin Exp Allergy 2008; 38: 466-472.

Papadopoulos NG, Stanciu LA, Papi A, et al. A defective type 1 response to rhinovirus in atopic asthma. Thorax 2002; 57: 328-332.

Durrani SR, Montville DJ, Pratt AS, et al. Innate immune responses to rhinovirus are reduced by the high-affinity IgE receptor in allergic asthmatic children. J Allergy Clin Immunol 2012; 130: 489-495.

Wark PA, Johnston SL, Bucchieri F, et al. Asthmatic bronchial epithelial cells have a deficient innate immune response to infection with rhinovirus. J Exp Med 2005; 201: 937-947.

Contoli M, Message SD, Laza-Stanca V, et al. Role of deficient type III interferon- $\lambda$ production in asthma exacerbations. Nat Med 2006; 12: 1023-1026.

Sly PD, Kusel M, Holt PG. Do early-life viral infections cause asthma?. J Allergy Clin Immunol 2010; 125: 1202-1205.

Bianco A, Sethi SK, Allen JT, et al. Th2 cytokines exert a dominant influence on epithelial cell expression of the major group human rhinovirus receptor, ICAM-1. Eur Respir J 1998; 12: 619-626.

Sethi SK, Bianco A, Allen JT, et al. Interferon- $\gamma$ downregulates the rhinovirus induced expression of intercellular adhesion molecule-1 (ICAM-1) on human airway epithelial cells. Clin Exp Immunol 1997; 110: 362-369.

Papi A, Johnston SL. Rhinovirus infection induces expression of its own receptor intercellular adhesion molecule 1 (ICAM-1) via increased NF-кB-mediated transcription. J Biol Chem 1999; 274: 9707-9720.

Moffatt MF, Kabesch M, Liang L, et al. Genetic variants regulating ORMDL3 expression contribute to the risk of childhood asthma. Nature 2007; 448: 470-473.

Bouzigon E, Corda E, Aschard H, et al. Effect of 17q21 variants and smoking exposure in early-onset asthma. $N$ Engl J Med 2008; 359: 1985-1994.

Smit LA, Bouzigon E, Pin I, et al. 17q21 Variants modify the association between early respiratory infections and asthma. Eur Respir J 2010; 36: 57-64.

Halapi E, Gudbjartsson DF, Jonsdottir GM, et al. A sequence variant on $17 \mathrm{q} 21$ is associated with age at onset and severity of asthma. Eur J Hum Genet 2010; 18: 902-908.

Calişkan M, Bochkov YA, Kreiner-Møller E, et al. Rhinovirus wheezing illness and genetic risk of childhood-onset asthma. N Engl J Med 2013; 368: 1398-1407. 
124 Halperin SA, Eggleston PA, Hendley JO, et al. Pathogenesis of lower respiratory tract symptoms in experimental rhinovirus infection. Am Rev Respir Dis 1983; 128: 806-810.

125 Bardin PG, Johnston SL, Pattemore PK. Viruses as precipitants of asthma symptoms II. Physiology and mechanisms. Clin Exp Allergy 1992; 22: 809-822.

126 Halperin SA, Eggleston PA, Beasley P, et al. Exacerbations of asthma in adults during experimental rhinovirus infection. Am Rev Respir Dis 1985; 132: 976-980.

127 Lemanske RF, Dick EC, Swenson CA, et al. Rhinovirus upper respiratory infection increases airway hyperreactivity and late asthmatic reactions. J Clin Invest 1989; 83: 1-10.

128 Fleming HE, Little FF, Schnurr D, et al. Rhinovirus-16 colds in healthy and in asthmatic subjects: similar changes in upper and lower airways. Am J Respir Crit Care Med 1999; 160: 100-108.

129 Cheung D, Dick EC, Timmers MC, et al. Rhinovirus inhalation causes long-lasting excessive airway narrowing in response to methacholine in asthmatic subjects in vivo. Am J Respir Crit Care Med 1995; 152: 1490-1496.

130 Bardin PG, Sanderson G, Robinson BS, et al. Experimental rhinovirus infection in volunteers. Eur Respir J 1996; 9: $2250-2255$.

131 Gern JE, Calhoun W, Swenson C, et al. Rhinovirus infection preferentially increases lower airway responsiveness in allergic subjects. Am J Respir Crit Care Med 1997; 155: 1872-1876.

132 Xepapadaki P, Papadopoulos NG, Bossios A, et al. Duration of postviral airway hyperresponsiveness in children with asthma: effect of atopy. J Allergy Clin Immunol 2005; 116: 299-304.

133 Sajjan U, Wang Q, Zhao Y, et al. Rhinovirus disrupts the barrier function of polarized airway epithelial cells. Am J Respir Crit Care Med 2008; 178: 1271-1281.

134 Petecchia L, Sabatini F, Usai C, et al. Cytokines induce tight junction disassembly in airway cells via an EGFR-dependent MAPK/ERK1/2-pathway. Lab Invest 2012; 92: 1140-1148.

135 Papadopoulos NG, Papi A, Psarras S, et al. Mechanisms of rhinovirus-induced asthma. Paediatr Respir Rev 2004; 5: 255-260.

136 Hosoda M, Yamaya M, Suzuki T, et al. Effects of rhinovirus infection on histamine and cytokine production by cell lines from human mast cells and basophils. J Immunol 2002; 169: 1482-1491.

137 Volovitz B, Faden H, Ogra PI. Release of leukotriene C4 in respiratory tract during acute viral infection. J Pediatr 1988; 112: 218-222.

138 Grünberg K, Sterk PJ. Rhinovirus infections: induction and modulation of airways inflammation in asthma. Clin Exp Allergy 1999; 29 Suppl. 2: 65-73.

139 Friedlander S, Busse W. The role of rhinovirus in asthma exacerbations. J Allergy Clin Immunol 2005; 116: 267-273.

140 Wark PA, Johnston SL, Moric I, et al. Neutrophil degranulation and cell lysis is associated with clinical severity in virus-induced asthma. Eur Respir J 2002; 19: 68-75.

141 Wark PA, Bucchieri F, Johnston SL, et al. IFN- $\gamma$-induced protein 10 is a novel biomarker of rhinovirus-induced asthma exacerbations. J Allergy Clin Immunol 2007; 120: 586-593.

142 Message SD, Laza-Stanca V, Mallia P, et al. Rhinovirus induced lower respiratory illness is increased in asthma and related to virus load and Th1/2 cytokine and IL-10 production. Proc Natl Acad Sci USA 2008; 105 : 13562-13567. 